\title{
Memory without context: amnesia with confabulations after infarction of the right
} capsular genu

\author{
Armin Schnider, Klemens Gutbrod, Christian W Hess, Gerhard Schroth
}

\begin{abstract}
Objective-To explore the mechanism of an amnesia marked by confabulations and lack of insight in a patient with an infarct of the right inferior capsular genu. The confabulations could mostly be traced back to earlier events, indicating that the memory disorder ensued from an inability to store the temporal and spatial context of information acquisition rather than a failure to store new information.

Methods-To test the patient's ability to store the context of information acquisition, two experiments were composed in which she was asked to decide when or where she had learned the words from two word lists presented at different points in time or in different rooms. To test her ability to store new information, two continuous recognition tests with novel non-words and nonsense designs were used. Recognition of these stimuli was assumed to be independent of the context of acquisition because the patient could not have an a priori sense of familiarity with them.
\end{abstract}

Results-The patient performed at chance in the experiments probing knowledge of the context of information acquisition, although she recognised the presented words almost as well as the controls. By contrast, her performance was normal in the recognition tests with non-words and nonsense designs.

Conclusion-These findings indicate that the patient's amnesia was based on an inability to store the context of information acquisition rather than the information itself. Based on an analysis of her lesion, which disconnected the thalamus from the orbitofrontal cortex and the amygdala, and considering the similarities between her disorder, WernickeKorsakoff syndrome, and the amnesia after orbitofrontal lesions, it is proposed that contextual amnesia results from interruption of the loop connecting the amygdala, the dorsomedial nucleus, and the orbitofrontal cortex.

$(\mathcal{F}$ Neurol Neurosurg Psychiatry 1996;61:186-193)

Keywords: amnesia; confabulation; capsular genu; recognition; context memory

Anterograde amnesia can be defined as a "profound defect in new learning [with] impair- ment in the conscious, deliberate recall of information". "However, various behavioural patterns indicate that the "amnestic syndrome" is not a single entity. Some patients are much more impaired in freely recalling than in recognising previously presented information, deny any failure of their memory, and sometimes confabulate spontaneously and in memory tests. This type of amnesia has been documented in patients with orbitofrontal and basal forebrain damage after rupture of an aneurysm of the anterior communicating artery, ${ }^{2-7}$ in some patients with paramedian thalamic infarction, ${ }^{89}$ and in the early course of Wernicke-Korsakoff syndrome. ${ }^{10}$ By contrast, some patients also fail to recognise and apparently feel entirely unfamiliar with previously presented information (indicating deficient information storage), are very concerned about the failure of their memory, and do not spontaneously confabulate. Distinct examples of this type of memory failure were seen in patients with severe amnesia after focal medial temporal lobe damage. ${ }^{11-13}$

Patients with orbitofrontal damage, ${ }^{14} 15$ Wernicke-Korsakoff syndrome, ${ }^{16}{ }^{17}$ and thalamic lesions ${ }^{18}$ have also been shown to fail to store the temporal order and the context of information acquisition, a disorder which-in subtler form-was also shown in patients with dorsal prefrontal lesions sparing the orbitofrontal area. ${ }^{19} 20$ Unfortunately, most reports did not provide any clinical observations as to the relevance of the disorder (behaviour in everyday life, insight, confabulations, etc). Although a loss of the temporal tag in memory was suggested by Van der Horst ${ }^{21}$ a long time ago as a possible mechanism of spontaneous confabulations, no data supporting this link have been presented so far.

We describe a patient who had severe amnesia after an infarct involving the right inferior capsular genu and anterior thalamic nucleus. Amnesia after capsular genu lesions has been described but the reports either failed to further characterise the type of memory failure or to describe its impact on the patients' lives. ${ }^{22} 23$ Our patient failed most recognition tasks because she felt falsely familiar with most distracter items. She had no insight into the failure of her memory and confabulated spontaneously and in response to questions, but confabulations seemed to be composed of elements of true events. In a series of experiments we tested the hypothesis that this memory disorder resulted from an inability to store the temporal and spatial context of information acquisition and was independent of the capac- 
ity to learn new information. The patient's lesion interrupted the connections between the thalamus and the prefrontal (including orbitofrontal) cortex. We propose an anatomical model for temporal order amnesia and confabulations, which integrates the evidence from our patient and reports of patients with Wernicke-Korsakoff syndrome and orbitofrontal damage.

\section{Case report}

A 62 year old housewife with an 11 year school education was admitted to the Department of Neurology for confusion and memory disturbances insidiously evolving over five days. She had a four year history of mild hypertension and diabetes mellitus, which had been well controlled with atenolol, diltiazem, and glibenclamid. At admission, she did not know why she was at the hospital and denied any memory problem. Physical examination was normal except for high blood pressure (190/95). Blood glucose was moderately raised $(9.8 \mathrm{mM})$ and lipid electrophoresis showed a decreased high density lipoprotein fraction. Cardiac examination was normal. Carotid Doppler ultrasound showed discrete plaques at the carotid bifurcation. Brain CT showed an isolated hypodense lesion involving the genu of the internal capsule and possibly the anterior thalamus on the right side. A diagnosis of right capsular genu infarction, presumably due to diabetes and hypertension, was made, and the patient was put on aspirin.

She remained severely amnestic. She never acknowledged any memory disturbance and maintained that she was in the hospital for her diabetes. She gave precise accounts of past

Table 1 Memory assessment

\begin{tabular}{|c|c|c|c|c|}
\hline \multirow[b]{3}{*}{ Task/Reference } & \multicolumn{4}{|c|}{ Time after onset } \\
\hline & \multicolumn{2}{|c|}{3 months } & \multicolumn{2}{|c|}{7 months } \\
\hline & Score & Percentile & Score & Percentile \\
\hline $\begin{array}{l}\text { Digit span forward }{ }^{65} \\
\text { Corsi block tapping }\end{array}$ & 5 & 20 & 5 & 20 \\
\hline \multirow{2}{*}{\multicolumn{5}{|c|}{$\begin{array}{l}\text { Wechsler memory scale }{ }^{65} \text { : } \\
\text { Logical memory }\end{array}$}} \\
\hline & & & & \\
\hline Immediate & 3 & $<1$ & 7 & $<1$ \\
\hline Delay & 1 & $<1$ & 2 & $<1$ \\
\hline \multicolumn{5}{|l|}{ Word associating learning: } \\
\hline Immediate & 10 & $<1$ & 11 & 5 \\
\hline Delayed & 2 & $<1$ & 3 & $<1$ \\
\hline \multicolumn{5}{|l|}{ California verbal learning test $^{28}$ : } \\
\hline Trial 1 & 2 & $<1$ & 3 & $<1$ \\
\hline Trial 5 & 4 & $<1$ & 9 & $<1$ \\
\hline Long delay free recall & 2 & $<1$ & 4 & $<1$ \\
\hline Long delay cued recall & 5 & $<1$ & 4 & $<1$ \\
\hline Recognition & 12 & $<1$ & 12 & $<1$ \\
\hline Perseverative errors & 4 & 45 & 0 & 84 \\
\hline Intrusions & 41 & $<1$ & 65 & $<1$ \\
\hline \multicolumn{5}{|l|}{ Rey-Osterrieth complex figure test: } \\
\hline Delayed Recall ${ }^{67}:$ & 3.5 & $<1$ & 9 & 20 \\
\hline \multicolumn{5}{|l|}{ Rey visual design learning test ${ }^{68}$ : } \\
\hline Trial 1 & 1 & $<1$ & 2 & $<1$ \\
\hline Trial 5 & 5 & 8 & 2 & $<1$ \\
\hline Delayed Recall & 2 & $<1$ & 2 & $<1$ \\
\hline Recognition & 12 & $<1$ & 7 & $<1$ \\
\hline Recognition, false positives (out of 15 ) & 6 & $<1$ & 4 & $<1$ \\
\hline \multicolumn{5}{|l|}{ Autobiographical memory interview ${ }^{30}$ : } \\
\hline \multicolumn{5}{|l|}{ Personal semantic memory } \\
\hline Childhood (maximum 21) & 21 & - & 21 & - \\
\hline Early adult life (maximum 21 ) & 19 & - & 21 & - \\
\hline Recent facts (maximum 21) & 14 & - & 17 & - \\
\hline \multicolumn{5}{|l|}{ Autobiographical } \\
\hline Childhood (maximum 9) & 9 & - & 9 & - \\
\hline Early adult life (maximum 9) & 9 & - & 9 & - \\
\hline Recent facts (maximum 9) & 4 & - & 3 & - \\
\hline
\end{tabular}

remote personal and public events back to childhood years but confabulated on events occurring after the stroke. She seemed to recognise the personnel on the ward but often confused their names or confabulated on the circumstances of their meeting. For example, when asked whether she recognised one of the examiners, she explained: "You are Dr S (correct). We did physiotherapy this morning (she had had physiotherapy, but not with Dr S), then we worked on the computer (she had regular computer training, but not that morning and never with Dr S) where you showed me a camel and other animals composed of dots (referring to a perceptual priming test taken two weeks previously)". Thus her confabulations appeared to consist of freely arranged elements of previous actual events.

She was discharged to her own home three months after the stroke. She needed regular assistance from her daughter because she was unable to organise her own household. She would forget to prepare the meals and would confuse appointments and events. For example, she retained a sample of urine every morning for several days stating that she had an appointment with her family doctor (she had actually had an appointment some days previously). Convinced that she had a good memory, she never used a shopping list and bought the same items several times, thus amassing for example, a considerable stock of toilet paper which she thought she had run out of. Her daughter thought that the patient's memory disturbance extended two to three years backwards. The patient was repeatedly astonished at the presence of "new" buildings in her town that had been constructed during the previous two to three years or at the decease of friends who had actually died in the same period.

\section{NEUROPSYCHOLOGICAL EVALUATIONS}

Neuropsychological evaluations were performed three and seven months after the stroke with essentially similar results. The patient had low average intelligence (WAIS$\mathrm{R}^{24}$ VIQ 92; PIQ 90; FIQ 90). Language and associated functions as well as visuoconstructive and visuospatial capacities, phasic alertness, cognitive speed, and interference control were normal. Whereas verbal fluency ${ }^{25}$ was normal, design fluency ${ }^{26}$ was slightly decreased. Concept identification ${ }^{27}$ was impaired, primarily due to many perseverative errors.

\section{MEMORY TESTING}

Formal tests disclosed a severe verbal and non-verbal anterograde amnesia (table 1). Unlike "typical" amnestic patients, however, she repeatedly surprised the examiners with details from previous tests. What appeared to be confabulations were-with virtually no exception-intrusions of material presented in previous tests or semantically related material. For example, she produced even more "intrusion errors" in the California verbal learning test $(\mathrm{CVLT})^{28}$ at the follow up examination after seven months, when form B was used, 
than after three months; almost all of these additional errors were intrusions from form $A$, which she had learned four months previously. Motor learning in a mirror drawing task ${ }^{29}$ was normal. Retrograde memory was intact except for the recent past: on the questionnaire of Kopelman et $a l^{30}$ she achieved perfect scores for the first two periods (childhood, adolescence, table 1). Only for the latest period (recent old memory), were her scores deficient and she confabulated on several items. In a famous faces recognition test she was shown pictures of the Swiss Bundesräte (members of the government) of the past five decades and asked to name them. Whereas her performance was similar to age matched controls for previous decades, she failed to name the Bundesräte presently in office (most of them have been in office for several years); her performance was more than 1 SD below the mean of five age matched controls. However, she correctly recognised their names from three choices.

\section{Methods \\ Because the patient's confabulations and intrusions in memory tests could mostly be traced back to earlier events or tests, we hypothesised that her amnesia was based on an inability to store the temporal order and spatial context of information acquisition rather than the information itself. Thus she would store new information but later fail to recall or recognise it because she would be ignorant as to what stored information per- tained to a particular situation. We composed experiments to explore whether she did indeed store new information and whether she had knowledge about the context of information acquisition.}

\section{FREE VERSUS CONSTRAINED RECOGNITION (EXPERIMENT 1)}

The patient achieved bad scores in recognition tasks due to many false positives. This experiment explored whether her spontaneous behaviour in recognition tests indeed reflected very poor knowledge about target items or whether she had better (implicit) knowledge about the target items than suggested by her spontaneous behaviour. We composed a recognition test with 16 line drawings from Snodgrass and Vanderwart ${ }^{31}$ which had been used in a perceptual priming task (test not detailed here; her performance was normal). Each target item was presented with three semantic foils (original drawings vertically arranged and printed on $21 \times 30 \mathrm{~cm}$ white sheets of paper). In the first run, she was asked to indicate the items that had been presented in the "test involving the drawings with dashed lines" (alluding to the masking of the drawings in the priming task) with no mention that only one item per series was correct (free recognition). Then a second run was made, in which she was allowed to select only one item per page (constrained recognition). This test was applied two days, one week, and one month after the priming test. A similar recognition task was composed with the items of two temporal order and spatial context memory tasks (described below). Each version of the recognition tasks was also given to two age matched controls.

TEMPORAL ORDER JUDGEMENT (EXPERIMENT 2) To test the ability to time label newly acquired information, two semantically matched lists with 10 common concrete words were composed. Both lists were learned in the same manner one hour apart. All 10 words from a list were orally presented and the patient was requested to recall all words aloud. To ensure learning of all words, the order of presentation was rotated by two words from trial to trial. Learning trials were repeated until all words were recalled in at least three trials. One hour after the last learning trial of list 2 , free recall of all words from both lists was tested. Then, a list of printed word pairs with one word from list 1 and one word from list 2 was presented. All words from list 1 were paired with all words from list 2 , once with the word from list 1 on the left, once with the word from list 2 on the left $(2 \times 10 \times 10$ words $=200$ word pairs). She was requested to indicate for each word pair which word had appeared in the first word list. One hour later, recognition of all words was tested by presenting each word with three semantic foils. This experiment was performed three months after the stroke. Because this task seemed very easy and was expected to yield a ceiling effect, only two age matched control subjects were tested.

\section{SPATIAL AND PERSONAL CONTEXT (EXPERIMENT 3)}

Even if the patient failed to time label stimuli, recognition would still be expected to be better if she recalled the context (place, person) of stimulus presentation. For example, recognition of priming task items should succeed based on knowledge about the stimulus context (the priming task), independent of the time of presentation. Two aspects of context memory were tested: attribution of a stimulus to the place where it had been presented (spatial context) and to the person who had presented it (personal context). The same word lists as in experiment 2 (performed four months previously) were used. The word lists were presented by two examiners in their distinctly different offices at the same time: after every second learning trial of a list, the patient was brought to the other examiner's office for two learning trials of the other word list until criterion was reached for both word lists. After one hour, recall was tested. Then 200 word pairs composed in the same way as in experiment 2 were presented by a neutral examiner in one of the examiners' offices and the patient was requested to indicate for each word pair which word had been presented in this room ("Which of these two words have you learned in this room today?"). Thirty minutes later, she was again presented with the 200 word pairs by one of the examiners in a neutral room and requested to indicate "which of these two words have you learned from me today?". This 
experiment was performed seven months after the stroke. As in experiment 1 , because this task seemed very easy and was expected to yield a ceiling effect, we tested only two age matched controls.

NEW LEARNING (EXPERIMENT 4)

If the patient's amnesia was based solely on failed contextual labelling of information, she should be able to learn new information and to retrieve it if the time and context of presentation could not be confused and would be irrelevant for recognition. This hypothesis could not be tested with meaningful stimuli because their recollection might be particularly dependent on contextual knowledge. We used the non-verbal learning test of Sturm and Willmes $\left(\right.$ NVLT) ${ }^{32}$ with nonsense designs and a verbal learning test (VLT) with non-words. Both tests consisted of 160 cards, each containing one stimulus. All cards were shown for three seconds, and the patient was asked to indicate for each stimulus whether she had seen it before. Both tests actually comprised eight series of 20 randomly ordered cards, each series containing eight recurring and 12 novel stimuli. The total number of recurrences was 56. The average interval between subsequent presentations of a stimulus was 60 seconds. The score was calculated as total number of correct recognitions minus total number of false positives. The normal values provided by Sturm and Willmes ${ }^{32}$ are based on a healthy control population of $n=400$ for the NVLT and $\mathrm{n}=314$ for the VLT. Normal means (SD) were: NVLT $32.9(10 \cdot 1)$; VLT 37.7 $(10 \cdot 7)$.

\section{Results}

EXPERIMENT 1: FREE VERSUS CONSTRAINED RECOGNITION

By contrast with the controls, the patient's free recognition was very unreliable: she felt familiar with all items that had actually been presented (perceptual priming items: 16 of 16 possible true positives; temporal order judgement and context memory tests: 20 of 20), but also with many or most distracter items (perceptual priming items: six of 48 possible false positives after two days, 36 after one week, 39 after one month; temporal order judgement and context memory tests: 23 and 25 of 60 possible false

Table 2 Context memory

\begin{tabular}{lccc}
\hline & Patient & Control 1 & Control 2 \\
\hline Temporal order judgment (experiment 2): & 8 & 12 & 11 \\
$\quad$ Free recall (maximum 20) & 103 & 180 & 181 \\
$\quad$ Correct temporal order judgments (maximum 200) & 16 & 19 & 20 \\
$\quad \begin{array}{l}\text { (maximumed recognition after one hour } \\
\text { Spatial and personal context memory (experiment 3): }\end{array}$ & 12 & 14 & 14 \\
$\quad$ Free recall (maximum 20) & 12 & 197 & 200 \\
$\quad$ Correct spatial context judgments (maximum 200) & 109 & 200 & 200 \\
$\quad$ Constrained recognition after one hour & 116 & 20 & 20 \\
\hline (maximum 20) & 18 & 200 \\
\hline
\end{tabular}

Free recall was tested one hour after learning of list 2 . Constrained recognition was tested as explained in experiment 1 . positives after one hour). The controls achieved perfect scores in these tests and had no false positives. The patient's recognition was much more precise in the constrained condition (perceptual priming items: 15, 13, and 14 of 16 possible true positives after two days, one week and one month; temporal order and context memory tests: 16 and 18 of 20 possible true positives after one hour). These results indicated that she had stored the test items considerably better than expected from free recognition.

EXPERIMENT 2: TEMPORAL ORDER JUDGEMENT Table 2 summarises the results. Recall after one hour, immediately before making the temporal order judgement, was not much worse than in the controls (however, she produced many intrusions). By contrast, her temporal order judgements were random ( $52 \%$ correct; chance level, 50\%), whereas the controls' judgements were $90 \%$ accurate (comparison of the patient and the two controls, $\chi^{2}(2)=$ $114, P=0.0001)$. In constrained recognition one hour after the temporal order judgement, she performed only slightly below the controls, indicating that her poor temporal order judgement did not simply reflect poor item storage.

\section{EXPERIMENT 3: SPATIAL AND PERSONAL \\ CONTEXT}

Table 2 summarises the results. The patient's free recall before testing judgement of context was comparable with the controls. Her judgement of context was random (spatial context, $108 / 200,55 \%$ ) or near random (personal context, 116/200, 58\%; random range, 100 (SD 13)), whereas the controls judged spatial and personal context of the words 99 to $100 \%$ correctly. Constrained recognition after one hour was comparable with the controls.

\section{EXPERIMENT 4: NEW LEARNING}

The patient's performance was normal in both tests: she achieved a score of 25 in the NVLT (29 correct; four false positives; percentile, 37) and 37 in the VLT (43 correct; six false positives; percentile, 56 ).

\section{LESION ANALYSIS}

Lesion analysis was based on an MRI (1.5 Tesla; STIR: $T R=3200 \mathrm{~ms}$, TEf $=19 \mathrm{~ms}$, $\mathrm{TI}=165 \mathrm{~ms}$ ) performed seven months after the stroke (figs 1 and 2). Axial images were parallel to the AC-PC line, and coronal sections were perpendicular to it. The damaged structures were determined based on comparison of the MRI with the atlases of Nieuwenhuys et $a l^{33}$ and Van Buren and Borke. $^{34}$ The lesion involved the inferior part of the genu of the right internal capsule and the right anterior thalamic nucleus (figs 1 and 2 , horizontal sections). It extended all along the anterior surface of the thalamus and ventrally below the level of the anterior commissure, which was spared, and included the anterior and inferior thalamic peduncle. The inferior part of the column of the fornix was possibly involved (fig 1, coronal sections), whereas the mamillothalamic tract was spared. 

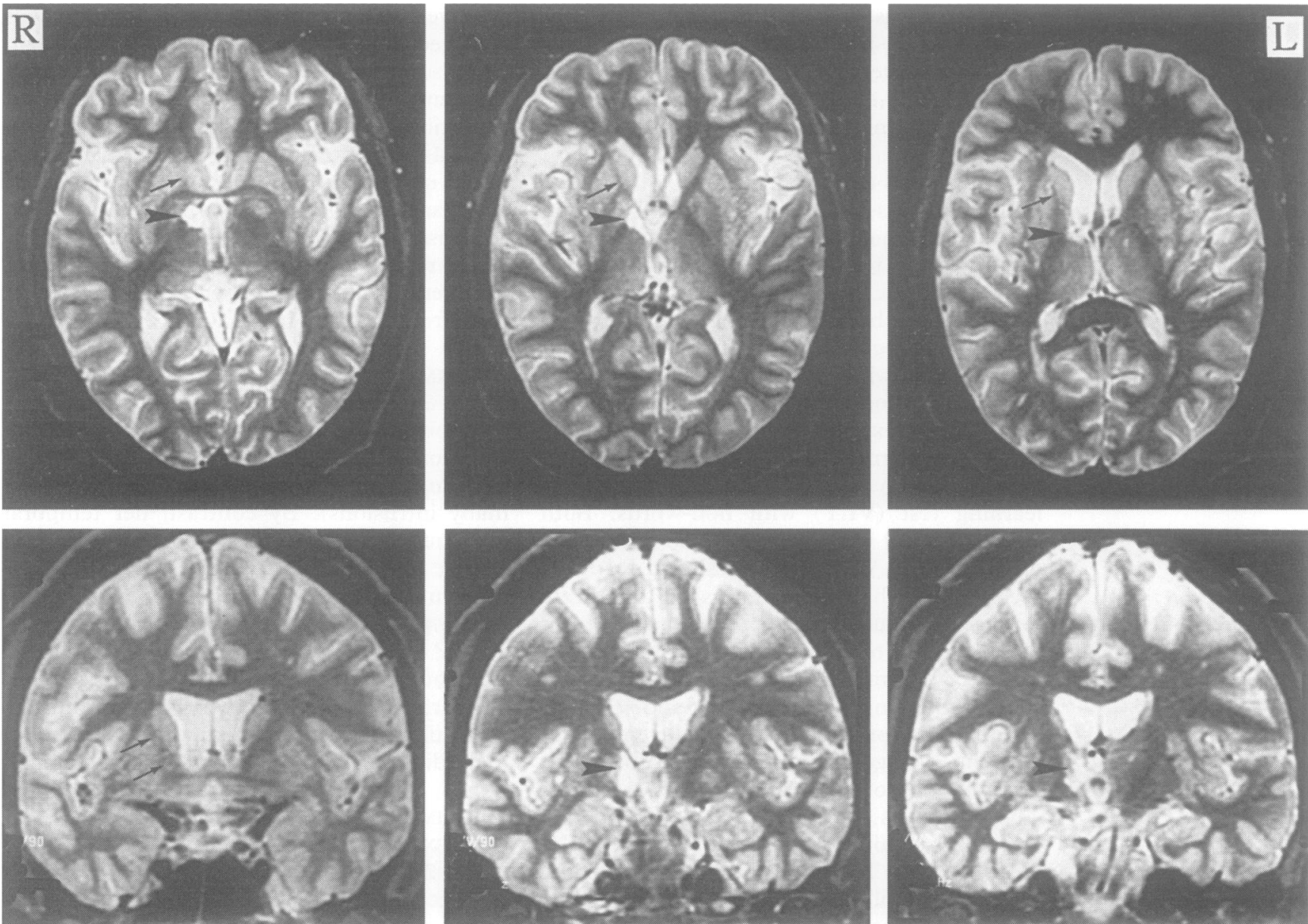

Figure 1 MRI seven months after stroke demonstrating the lesion of the right capsular genu and anterior thalamus (bold arrowhead). Axial slices are parallel, coronal slices perpendicular to the AC-PC line. Note the atrophy of the anterior limb of the right internal capsule (thin arrows), which contains the projections of the dorsomedial thalamic nucleus with the prefrontal and orbitofrontal cortex.

There was severe atrophy of the anterior limb of the right internal capsule. The dorsomedial and dorsolateral nucleus were spared. The lesion most likely represents infarction in the distal territory of the posterior choroidal branches. ${ }^{35}$ There were some additional tiny lesions of the white matter not exceeding typical age related changes.
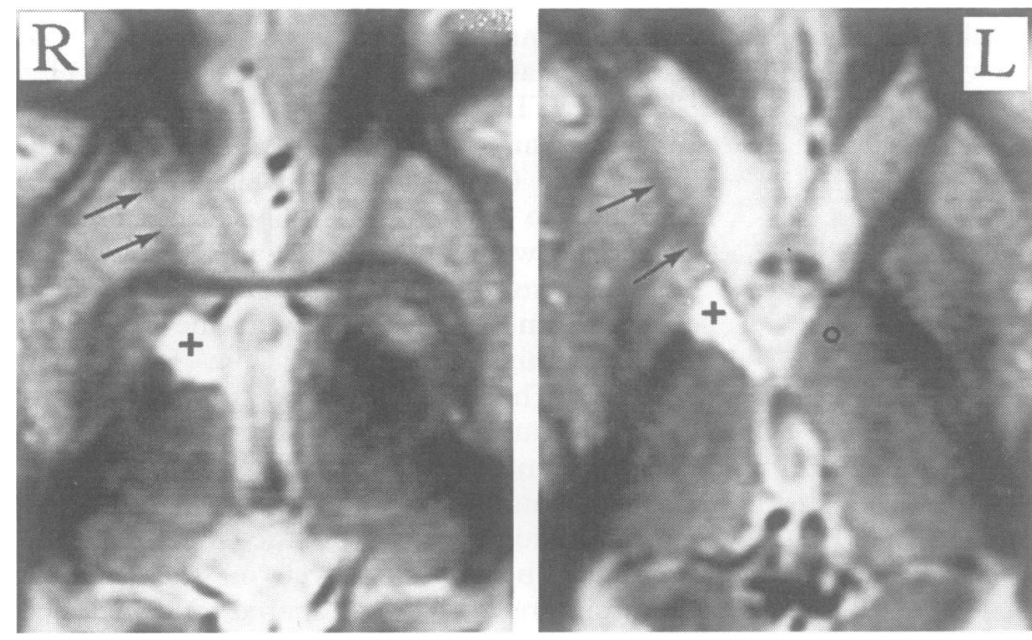

Figure 2 Details from figure 1 (axial slices). The lesion ( + ) involves the capsular genu and the anterior thalamic nucleus (the small circle $(\bigcirc)$ indicates the position of the left anterior nucleus). Note the atrophy of the anterior limb of the right internal capsule (thin arrows) including the anterior thalamic peduncle (left picture).

\section{Discussion}

This patient's amnesia was disabling in everyday life and severe by traditional measures of memory functions (table 1). She did not seem to realise her failures; she was unconcerned and denied any memory problem. Some behavioural features suggested that she stored information considerably better than implied by her test scores: although she often confused previously met people and earlier events, she seemed to be familiar with them; her spontaneous confabulations could mostly be traced back to actual events, and the confabulations produced in memory tests were mostly intrusions from earlier tests. These behavioural findings motivated a series of experiments to test whether her memory disorder was based on an inability to store the context (temporal order, space, etc) of information acquisition rather than the information itself.

The patient's bad performance in recognition tasks resulted from false familiarity with most distracter items. This impairment is reminiscent of the patient of Delbecq-Derouesné et $a l^{36}$ who showed particularly bad recognition with relatively preserved recall (however, with abundant confabulations!) after extensive, primarily right sided frontal and anterior temporal damage after rupture of an aneurysm of the anterior communicating artery. Delbecq-Derouesné et al explained the dis- 
crepancy between recall and recognition with different strategies: recall requires an active searching strategy whereas recognition is based on a familiarity judgement. ${ }^{36}$ This interpretation is supported by our finding that the patient's recognition significantly improved when she was forced to use a searching strategy for recognition, too (forced choice of one item only; experiment 1). Delbecq-Derouesné et al concluded that their patient's bad recognition "does not result from any lack of knowledge but rather from his inability to distinguish his experience of remembering from another kind of misleading subjective experience triggered by the distracters" but did not experimentally substantiate this idea. ${ }^{36}$ We hypothesised that our patient's false familiarity with distracter items in recognition tasks was based on an inability to coencode the time and the spatial context of the occasion in which information was acquired. Any type of information stored without these attributes cannot be related to a particular event and will easily be confused with elements of different events. Experiments 2 and 3 were consistent with our hypothesis: she recalled the temporal order and the context (place and person) in which word lists were presented at or near chance. This interpretation predicted that recognition would be normal if the context of information acquisition was irrelevant. We tested this prediction with a recognition task involving novel non-words and nonsense designs ${ }^{32}$ because the patient could not have an a priori sense of familiarity with these stimuli (experiment 4 ). She performed in the normal range for both types of stimuli, confirming that her memory disorder was not based on an inability to store new information.

Our findings offer an interpretation of confabulations, the mechanism for which has been a matter of debate. Amnesia, albeit typically present, does not correlate with the severity of confabulations. ${ }^{37-39}$ Our patient indicates that an inability to store item specific information is not even necessary for confabulations (experiment 4). A combination of amnesia with prefrontal damage has been postulated. ${ }^{54041}$ Although confabulations are often associated with deficient performance on frontal lobe tasks, it is unclear what "frontal dysfunction" would explain confabulations. Impaired "self monitoring" has been alleged, ${ }^{39} 42$ but the physiological basis of "self monitoring" is unclear. Van der Horst speculated a long time ago that spontaneous confabulations resulted from an inability to maintain temporal order in memory. ${ }^{21}$ Our study lends experimental support to this idea. We propose that confabulations are based on an inability to temporally and contextually label information, resulting in confusion of elements of memory that do neither temporally nor contextually belong together. Confabulations may thus not reflect a subject's desire "to fill gaps in memory" 43 but rather mirror the subject's spontaneous recollection of information stored with insufficient contextual clues.

How does the patient's lesion account for her memory disorder? Her lesion involved the connections of the thalamus with the hippocampus (anterior nucleus lesion) and with the amygdala and orbitofrontal cortex (capsular genu lesion). This lesion thus interrupted both limbic loops considered important for memory functions (hippocampus-fornix-anterior thalamic nucleus-cingulum-hippocampus; amygdala-dorsomedial thalamic nucleusorbitofrontal cortex-amygdala). ${ }^{44}$ Whether damage to the anterior thalamic nucleus is sufficient to cause amnesia in humans has not been established due to scarcity of patients with isolated lesions but was suggested by animal experiments. ${ }^{45}$ As the anterior nucleus has strong connections with the hippocampus (through the fornix and cingulum) but no significant connections with the amygdala and orbitofrontal cortex, ${ }^{46-48}$ it may be assumed that the behavioural syndrome emanating from damage to the anterior nucleus would be qualitatively similar to hippocampal rather than orbitofrontal damage. We suggest that the patient's anterior nucleus lesion was responsible for her relatively inferior, albeit normal, recognition of nonsense designs as compared with non-words (experiment 4). However, it is unlikely that the anterior nucleus lesion accounted for the main features of her amnesia - that is, the confabulations, false familiarity in recognition tasks, and lack of insight-because these are not characteristics of the amnesia after hippocampal damage. ${ }^{1213} \mathrm{We}$ suggest that these features were due to damage of the loop connecting the amygdala, the orbitofrontal cortex, and the dorsomedial nucleus. Whether amygdala damage alone may produce amnesia is unknown because no single case with a previously healthy brain and isolated damage to the amygdala has ever been reported. Patients with inherited, slowly progressive damage to the amygdala (thus allowing continuous compensation of the damage) have been reported to show relatively mild, albeit significant, memory deficits. ${ }^{49} 50$ Animals' performance in recognition tasks was markedly worse after combined lesions of the hippocampus and amygdala, indicating a significant role of the amygdala in memory processes. ${ }^{51}$ But this finding also seems to depend on the specific type of recognition task used and has been strongly contested. ${ }^{52}$ However, animal experiments may be of limited value in discussing our patient's amnesia because they depend on recognition tasks (our patient's recognition performance was normal under specific circumstances; experiment 4) and ignore some behavioural features that are so essential to human amnesia, such as free recall, confabulations, and insight.

Paramedian thalamic infarction may produce an amnesia which is initially accompanied by confabulations. Chronic confabulations have also been described. ${ }^{9}$ Chronic amnesia after paramedian thalamic infusion requires a relatively anterior thalamic lesion involving the area which is normally supplied by the polar artery. ${ }^{53-55}$ Such lesions regularly involve not only the mamillothalamic tract but 
also the internal medullary lamina, which contains the connections of the dorsomedial nucleus with the amygdala (unidirectional afferents) and the orbitofrontal cortex (reciprocal connections). ${ }^{535566}$ The amnesia due to Wernicke-Korsakoff syndrome, which is often initially indicated by confabulations, also seems to best correlate with the extent of damage to the dorsomedial nucleus ${ }^{10}$; this correlation might be dependent on the anterior extension of damage - that is, interruption of the fibres from the amygdala on the way to the orbitofrontal cortex. The lesions associated with amnesia after rupture of an aneurysm of the anterior communicating artery involve the basal forebrain (septal nuclei, medial forebrain bundle, and other subcortical structures), the medial orbitofrontal cortex, or both. ${ }^{2356}$ Patients with combined lesions of the basal forebrain and the orbitofrontal cortex seem to produce markedly more intrusions (confabulations) in memory tests than patients with subcortical basal forebrain lesions sparing the orbitofrontal cortex. ${ }^{57}$ Our patient's lesion, which caused a type of amnesia similar to medial thalamic and orbitofrontal damage, disconnected the dorsomedial nucleus from both the amygdala and the prefrontal (including orbitofrontal) cortex as it involved the inferior and anterior thalamic peduncles, ${ }^{465558}$ as shown by the atrophy of these fibres in the MRI seven months after the stroke (figs 1 and 2). Her lesion thus provides a link between the lesions causing amnesia after paramedian thalamic infarction and orbitofrontal damage. We suggest that her amnesia, which-similar to the amnesia after paramedian thalamic infarction and orbitofrontal damage-was characterised by confabulations and lack of insight, was based on disconnection of the loop connecting the amygdala, the orbitofrontal cortex, and the dorsomedial thalamic nucleus.

We can only speculate why a unilateral right sided lesion was sufficient to cause such a pervasive memory disorder. Initial confabulations were described after a unilateral right paramedian thalamic infarct. ${ }^{59}$ Patients with surgical removal of the right frontal lobe were found to be more impaired in making recency judgements about newly acquired information than patients with left frontal ablation. ${ }^{60}$ Additionally, talkative behaviour (hyperverbalisation) was demonstrated after right, but not left, frontal damage. ${ }^{61}$ It is therefore possible that patients with a similar lesion on the left side would not be as amnestic as our patient and would not confabulate.

Finally, why would the connections between the amygdala, the prefrontal cortex, and the dorsomedial nucleus be so important for memory? Animal studies have shown that both the amygdala and the prefrontal cortex process stimulus-reward associations and may thus be important for the filtering out of behaviourally relevant information. A temporal integrative function of these structures has been proposed. ${ }^{62}{ }^{63}$ Even though the rewards and punishments used in animal experiments hardly rival the complexities of human emotions, we propose- - based on these studies- that the attribution of an "emotional" or behavioural significance to a stimulus by the amygdala and the prefrontal cortex may be the correlate of the temporal and contextual label of information. Because the amygdala and the orbitofrontal cortex have direct connections, the role of the dorsomedial nucleus is unclear. Recent studies concerning the visual system suggest a mechanism by which the dorsomedial-orbitofrontal connection might be critical. The visual cortex does not passively absorb information from neurons in the lateral geniculate body but seems to synchronise their activity. ${ }^{64}$ This feedback probably leads to stimulus amplification and may be essential for visual feature detection. A similar function may pertain to the orbitofrontal cortex: it might synchronise relay in the dorsomedial nucleus, a mechanism which might be important for "emotional" feature detection.

We thank Professor DY von Cramon for helpful discussion, Dr J Bogousslavsky for advice on the localisation of the lesion, Dr W Sturm and Dr K Willmes for allowing us to use their recognition test, and Dr D Dreier for performing the MRI. The study was supported by grant No 32-40 432.94 from the Swiss National Science Foundation.

1 Bauer RM, Tobias B, Valenstein E. Amnesic disorders. In: Heilman KM, Valenstein E, eds. Clinical neuropsychology. New York: Oxford University Press, 1993:523-602.

2 Alexander MP, Freedman M. Amnesia after anterior communicating artery aneurysm rupture. Neurology 1984; municatin

3 Damasio AR, Graff Radford NR, Eslinger PJ, Damasio $\mathrm{H}$ Kassel N. Amnesia following basal forebrain lesions. Arch Neurol 1985;42:263-71.

4 DeLuca J, Cicerone KD. Confabulation following aneurysm of the anterior communicating artery. Cortex 1991;27:417-23.

5 DeLuca J. Predicting neurobehavioral patterns following anterior communicating artery aneurysm. Cortex 1993; 29:639-47.

6 Hanley JR, Davies ADM, Downes JJ, Mayes AR. Impaired recall of verbal material following rupture and repair of an anterior communicating artery aneurysm. Cognative Neuropsychology 1994;11:543-78.

7 DeLuca J, Diamond BJ. Aneurysm of the anterior communicating artery: a review of neuroanatomical and neunicating artery: a review of neuroanatomical and neuropsychologica

8 Guberman A, Stuss D. The syndrome of bilateral paramedian thalamic infarction. Neurology 1983;33:540-6.

9 Hodges JR, McCarthy RA. Autobiographical amnesia resulting from bilateral paramedian thalamic infarction A study in cognitive neurobiology. Brain 1993;116 921-40.

10 Victor M, Adams RD, Collins GH. The Wernicke-Korsakoff syndrome. 2nd ed. Philadelphia: FA Davis, 1989

11 Scoville WB, Milner B. Loss of recent memory after bilatera hippocampal lesions. $\mathcal{F}$ Neurol Neurosurg Psychiatry 1957; 20:11-21.

12 Schnider A, Regard M, Landis T. Anterograde and retrograde amnesia following bitemporal infarction. Behav Neurol 1994;7:87-92.

13 Schnider A, Gutbrod K, Ozdoba C, Bassetti C. Very severe amnesia with acute onset after isolated hippocampal amnesia with acute onset after isolated hippocampal damage due to systemic lupus ery

14 Shoqeirat MA, Mayes AR. Disproportionate incidental spatial-memory and recall deficits in amnesia. Neuropsychologia 1991;29:749-69.

15 Eslinger P, Damasio AR. Behavioral disturbances associated with rupture of anterior communicating artery Semin Neurol 1984;4:385-9.

16 Shimamura AP, Squire LR. A neuropsychological study of fact memory and source amnesia. F Exp Psychol Learn Mem Cogn 1987;13:464-73.

17 Hunkin NM, Parkin AJ. Recency judgements in WernickeKorsakoff and post-encephalitic amnesia: influences of proactive interference and retention interval. Cortex 1993;29:485-99.

18 Parkin AJ, Rees J, Hunkin NM, Rose PE. Impairment of memory following discrete thalamic infarction. Neuropsychologia 1994;32:39-51.

19 Milner B, Petrides M, Smith ML. Frontal lobes and the temporal organization of memory. Human Neurobiology 1985;4:137-42.

20 Shimamura AP, Janowsky JS, Squire LR. What is the role of frontal lobe damage in memory disorders? In: Levin HS, Eisenberg HM, Benton AL, eds. Frontal lobe function and dysfunction. New York: Oxford University Press, and dysfunction.

21 Van der Horst L. Über die Psychologie des Korsakow- 
syndroms. Monatsschrift für Psychiatrie und Neurologie 1932;83:65-84.

, Von Cramon DY, Hofmann E, Sick Kinzler P. Verbal memory deterioration after unilateral infarct of the internal capsule in an adolescent. Cortex 1990;26:597-609.

23 Tatemichi TK, Desmond DW, Prohovnik I, Cross GTI, Mohr JP, Stern Y. Confusion and memory loss from capsular genu infarction. Neurology 1992;42:1966-79.

24 Tewes U. HAWIE-R: Hamburger-Wechsler Intelligenztest für Erwachsene. Handbuch und Testanweisung. Bern: Huber, 1991.

25 Perret E. Gehirn und Verhalten. Neuropsychologie des Menschen. Bern: Huber Verlag, 1973.

26 Regard M, Strauss E, Knapp P. Children's production on verbal and non verbal fluency tasks. Perc Mot Skills 1982;55:839-44

27 Heaton RK. Wisconsin card sorting test. Odessa: Psychological Assessment Resources, 1981.

28 Delis DC, Kramer JH, Kaplan E, Ober BA. The California verbal learning test. New York: Psychological Corporation, 1987 .

29 Schnider A, Gutbrod K, Hess CW. Motion imagery in Parkin A, Gutbrod K, Hess CW: Motion in

30 Kopelman MD, Wilson BA, Baddeley AD. The autobiographical memory interview: a new assessment of autobiographical and personal semantic memory in amnesic patients. $\mathcal{F}$ Clin Exp Neuropsychol 1989;11:724-44.

31 Snodgrass JG, Vanderwart M. A standardized set of 260 pictures: norms for name agreement, image agreement, familiarity, and visual complexity. F Exp Psychol Hum Learn Mem 1980;6:174-215.

32 Sturm W, Willmes K. NVLT bzw. VLT-Nonverbaler und Verbaler Lerntest. Mödling: Dr G Schuhfried GmbH, 1995.

33 Nieuwenhuys R, Voogd J, van Huijzen C. The human central nervous system. 3rd ed. Berlin: Springer, 1988.

34 Van Buren JM, Borke RC. Variations and connections of the human thalamus. Vol 2: variations of the human diencephalon. Berlin: Springer, 1972

35 Plets C, De Reuck J, Van der Eecken H, Van den Bergh R. The vascularization of the human thalamus. Acta Neurol Belg 1970;70:687-770.

36 Delbecq-Derouesné J, Beauvois MF, Shallice T. Preserved recall versus impaired recognition. Brain 1990;113: 1045-74.

37 Mercer B, Wapner W, Gardner H, Benson DF. A study of confabulation. Arch Neurol 1977;34:429-33.

38 Kapur N, Coughlan AK. Confabulation and frontal lobe dysfunction. I Neurol Neurosurg Psychiatry 1980;43: $461-3$

39 Benson DF. The neurology of thinking. New York: Oxford University Press, 1994

40 Stuss DT, Alexander MP, Lieberman A, Levine H. An extraordinary form of confabulation. Neurology 1978;28: $1166-72$.

41 Kopelman MD. Two types of confabulation. 7 Neurol Neurosurg Psychiatry 1987;50:1482-7.

42 Shapiro BE, Alexander MP, Gardner H, Mercer B. Mechanisms of confabulation. Neurology 1981;31: 1070-6.

43 American Psychiatric Association. DSM-IV. Diagnostic and statistical manual of mental disorders. 4th ed. Washington, DC: American Psychiatric Association, 1994.

44 Mishkin M. A memory system in the monkey. Phil Trans $R$ Soc Lond 1982;298:85-95.

45 Aggleton JP, Sahgal A. The contribution of the anterior thalamic nuclei to anterograde amnesia. Neuropsychologia 1993;31:1001-19.
46 Jones EG. The thalamus. New York: Plenum Press, 1985.

47 Raisman G, Cowan WM, Powell TPS. An experimental analysis of the efferent projection of the hippocampus. analysis of the efferent

48 Mufson EJ, Pandya DN. Some observations on the course and composition of the cingulum bundle in the rhesus monkey. 7 Comp Neurol 1984;225:31-43.

49 Tranel D, Hyman BT. Neuropsychological correlates of bilateral amygdala damage. Arch Neurol 1990;47: 349-55.

50 Babinsky R, Calabrese P, Durwen HF, et al. The possible contribution of the amygdala to memory. Behav Neurol 1993;6:167-70.

51 Mishkin $M$. Memory in monkeys severely impaired by combined but not by separate removal of amygdala and hippocampus. Nature 1978;273:297-8.

52 Zola-Morgan S, Squire LR, Amaral DG. Lesions of the amygdala that spare adjacent cortical regions do not impair memory or exacerbate the impairment following lesions of the hippocampal formation. $尹$ Neurosci 1989 ; 9:1922-36.

53 Von Cramon DY, Hebel N, Schuri U. A contribution to the anatomical basis of thalamic amnesia. Brain 1985 ; 108:993-1008.

54 Gentilini M, De Renzi E, Crisi G. Bilateral paramedian thalamic artery infarcts: report of eight cases. $\mathcal{f}$ Neurol Neurosurg Psychiatry 1987;50:900-9.

55 Graff-Radford NR, Tranel D, Van HGW, Brandt JP. Diencephalic amnesia. Brain 1990;113:1-25.

56 Markowitsch HJ, Von Cramon DY, Schuri U. Mnestic performance profile of a bilateral diencephalic infarct patien with preserved intelligence and severe amnesic disturbances. F Clin Exp Neuropsychol 1993;15:627-52.

57 Irle E, Wowra B, Kunert HJ, Hampl J, Kunze S. Memory disturbances following anterior communicating artery rupture. Ann Neurol 1992;31:473-80.

58 Amaral DG, Price JL, Pitkänen A, Carmichael ST. Anatomical organization of the primate amygdaloid complex. In: Aggleton JP, ed. The amygdala. Neurobiological plex. In: Aggleton JP, ed. The amygdala. Neurobiological aspects of emotion, memory, and men

59 Foglia P, Perini M, Vanzulli F. Pure amnesia in a case of right thalamic lesion. Ital $\mathcal{f}$ Neurol Sci 1991;12:211-3.

60 Milner B, Corsi P, Leonard G. Frontal-lobe contribution to recency judgements. Neuropsychologia 1991;29: 601-18.

61 Kolb B, Taylor L. Affective behavior in patients with localized cortical excisions: role of lesion site and side. Science 1981;214:89-91.

62 Fuster JM. The prefrontal cortex. Anatomy, physiology, and neuropsychology of the frontal lobes. 2nd ed. New York: neuropsychology of
Raven Press, 1989.

63 Kesner RP. Learning and memory in rats with an emphasis on the role of the amygdala. In: Aggleton JP. The amygon the role of the amygdala. In: Aggleton JP. The amygdala. Neurobiological aspects of emotion, memory, and ment
dysfunction. New York: Wiley Liss Inc 1992:379-99.

64 Sillito AM, Jones HE, Gerstein GL, West DC. Featurelinked synchronization of thalamic relay cell firing induced by feedback from the visual cortex. Nature 1994, 369:479-82.

65 Wechsler D. A standardized memory scale for clinical use. $\mathcal{F}$ Psychol 1945;19:87-95.

66 Milner B. Interhemispheric differences and psychological processes. Brit Med Bull 1971;27:273-7.

67 Rey A. Test de copie et de reproduction de mémoire de figures géometriques complexes. Paris: Centre de Psychologie, 1958.

68 Rey A. L'examen clinique en psychologie. Paris: Presses universitaires de Frances, 1964. 